\title{
ANYTHING BUT GOLD THE GOLDEN CONSTANT REVISITED
}

Jean-François Carpantier

\section{DISCUSSION PAPER | 2020 /36}




\title{
Anything but gold The golden constant revisited
}

\author{
Jean-François Carpantier \\ Corresponding member, IRES, UCLouvain, Belgium
}

Version 20 October 2020

\begin{abstract}
This paper revisits the golden constant - the gold property of keeping a constant purchasing power - via a comparison with a set of 17 commodities (energy, metals, agricultural products). We first use graphical devices of the CPI-deflated commodity prices, then stationarity tests designed to assess how fast the real prices of the commodities revert to their "constant" and, finally, measurements of their convergence speed. We find that the real price of gold is far from a constant, farther than the real price of most other commodities. We also note that the mean reversion of gold real price to its constant/average is weaker and slower than for most other commodities. These findings suggest that most commodities do a better job than gold when it comes to keeping a constant purchasing power. A portfolio of commodities would provide a liquidity similar to gold, while offering to investors a more stable protection against inflation.
\end{abstract}

Keywords: gold; inflation; safe haven; portfolio diversification; hedging; commodities

JEL Classification: C22; G10; G11; G15; N20

The drivers behind the high trading activity of the gold market are relatively well known and go beyond its liquidity. They relate to its presumed properties. The precious material is indeed considered as a protection against the depreciation of the US dollar, a protection against global inflation, a powerful portfolio diversification tool thanks to its low correlation with traditional assets and finally as a refuge from the uncertainties of any order, such as financial crashes, geopolitical events, climatic hazards (Piffer and Podstakski, 2018)).

The purpose of this paper is to examine more closely one of these properties, namely the protection against inflation, that is, the stability of the gold purchasing power over time - the "golden constant". Gold certainly played a central role in the international monetary system for decades/centuries, but gold is also a physical asset and, as such, a commodity like many others. As for platinum, oil or corn, its price is expected to be connected to the general price level. Our contribution therefore consists in documenting and comparing the performance of gold as a hedge against inflation with a set of 17 alternative commodities, in view to ultimately see if its past monetary role makes gold still the best commodity for being isolated from inflation.

The empirical approach is split in 3 steps. First, we update the core graphics of Erb and Harvey $(2013,2017)$ dedicated to the golden constant, which documents the real price of gold (gold price adjusted for inflation) over the sample 1975 to 2019, and 
compare it to evolution of the real price of a set of 17 alternative commodities. Second, we test the behaviour of the real price of gold in order to determine whether it returns statistically to its unconditional average, in other words a constant purchasing power, or whether it oscillates in the manner of a non-stationary series. We perform this analysis on gold and compare the results with those obtained on the alternative commodities of our sample. This comparison relies on several tests, some being designed to neutralize the impact of structural changes or the lack of power of standard non-stationarity tests. Finally, we estimate the speed of convergence of the real price of gold towards its constant, that is how fast deviations from a constant purchasing power are corrected. The speed is measured using the concept of half-life, which is the average time required for a series to fill half the distance separating its unconditional average (its constant). Given both our results and the lack of consensus in the empirical literature (Chevallier and lelpo, 2013) on whether or not the commodities are stationary, we use 3 methods designed for stationary, quasi-nonstationary and non-stationary series, respectively. Rather than limiting ourselves, with relative arbitrariness, to one set of results, we discuss them all and report them in a synoptic table.

It is not betraying the suspense to announce that the mythological status of gold on the markets is somewhat excessive in view of the comparative results that we present below.

\section{Gold properties}

\subsection{Hedge against the dollar}

Many studies show that gold partly offsets changes in the US dollar, implying that gold is an effective hedge against the dollar (Capie et al. 2005, Pukthuantong and Roll 2011). This result, however, stems mechanically from the link with its unit of account, which is precisely the dollar. When the intrinsic value of the dollar declines, the international price of gold, expressed in dollars, increases. Likewise, when the intrinsic value of the dollar increases, the price of gold falls because the international markets are satisfied with less dollars for an ounce of gold. The hedge against the fluctuations of the dollar, however, hardly goes beyond this mechanical bond to the unit of account. Pukthuantong and Roll (2011) showed empirically that this correlation of the price of gold and the dollar also applies to other major currencies (euro, yen, pound sterling). An appreciation of the yen automatically leads to a decrease in the price of gold expressed in yen. As found by the authors, this property is not specific to the dollar.

\subsection{Hedge against market declines}

Then, the fund managers give generally a prominent place to gold because of its diversification power in stock/bond portfolios. For example, Baur and Lucey (2010) showed that gold has a negative correlation with equities (for the United States, the United Kingdom, but not for Germany). This negative correlation reduces the risk of a portfolio on average (but not necessarily in times of crisis).

\subsection{Hedge against disasters}

Third, gold is widely perceived as a safe haven asset, that is, a protection against disasters. Coudert and Raymond (2011) found in a sample from 1978 to 2009 that the correlation between gold and equities is close to zero during recessions and, 
overall, during periods of market decline. It is worth noting that these results hold on average, that is, not on all recessions or on all countries. Baur and McDermott (2010) also found that gold is a safe haven for the US and the Europe, but not for Australia, Canada, Japan and major emerging economies such as the BRICs. This safe haven property is also documented by Piffer and Podstawksi (2018) who showed the ability of gold to capture market uncertainty related to geopolitical shocks, natural disasters and judicial decisions.

\subsection{Golden Constant}

A fourth property of gold is its ability to maintain a stable value in terms of purchasing power. Erb and Harvey (2017) named "golden constant" this link between gold and the inflation. They showed that this link holds in the United States as well as in the 23 countries of their sample. The value of gold is bound to the value of all consumer goods. It is one of the essential characteristics of gold, to be both a financial product and a consumer (durable) good.
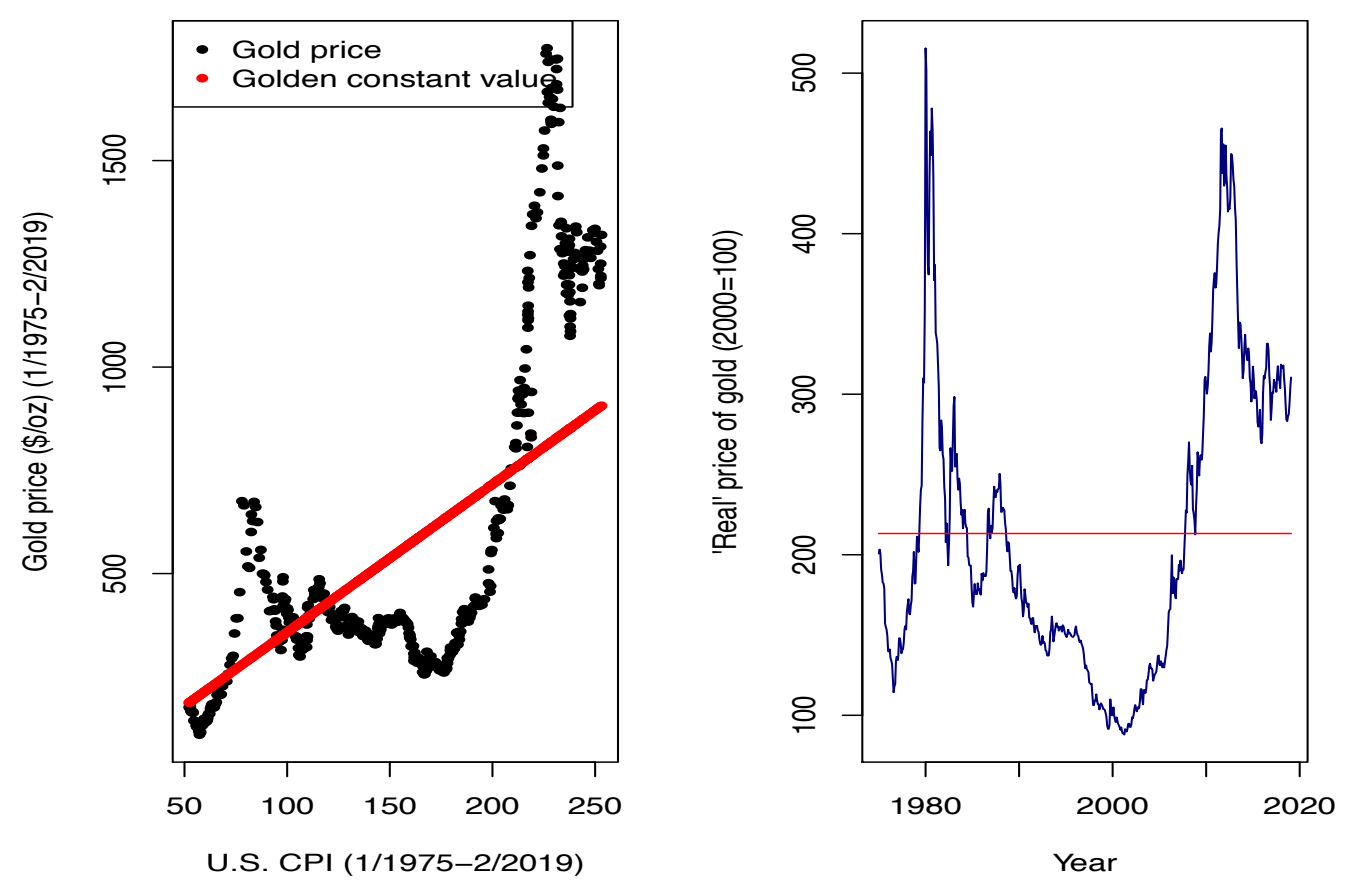

Figure 1: gold price vs price level (1a) and the real price of gold (1b)

(1a) The golden constant value is derived by multiplying the value of the U.S. Consumer Price Index by the average real price of gold (which is the average of the nominal price of gold divided by the U.S. Consumer Price Index). (1b) The real price of gold is the nominal U.S. dollar price of an ounce of gold divided by the U.S. Consumer Price Index, as standardized $2000=100$. The average price of gold is the average of the real price of gold over the period 1/1975-2/2019. Graphs updated from Erb and Harvey (2017).

Two graphs inspired from Erb and Harvey (2017) illustrate this relationship. Figure 1a shows the link between the USD gold price (vertical axis) and the level of the US consumer price index (CPI) over the sample 1975-2019. The upward sloping line corresponds to the (nominal) price required for gold to maintain its constant purchasing power. As shown on Figure 1a, the gold price deviates considerably from the constant, giving only weak support to the golden constant theory. Figure $1 \mathrm{~b}$ shows the evolution of the real price of gold from 1975 to 2019, with a horizontal line showing the average 
real price of the observation period. It turns out that the gold constant is graphically not valid in the short term, as gold takes many months before reverting back to its average. Erb and Harvey (2013) suggested that the golden constant is only effective over the centuries, and not over the usual horizon of an investor.

Similarly, Batten et al. (2014) studied the cointegration of the price of gold and the CPI and showed that this relationship is fragile and valid only in certain sub-windows of their sample.

\section{Empirical strategy}

The object of this study is to shed new critical light on the presumed property of gold to maintain a constant real value, that is, to maintain a stable purchasing power. Our original approach consists in comparing the performance of gold with that of other commodities, in order to check whether this monetary role that gold has played in the past gives it today properties that other commodities do not have.

\subsection{Data}

We use commodity price data from the World Bank (the "Pink Sheet") ${ }^{1}$, data provided in US dollars, and at monthly frequency, over the period January 1960-February 2019. Given the international monetary role played by gold until the early 1970s, we restrict our sample to the period 1975/01-2019/2, that is, 530 monthly observations. The World Bank database has 72 series, of which we keep 18 of the most traded series in the world. The series excluded from our sample were so for the following reasons: redundancy with a selected series, missing values on part of the analysis window, commodities costly to store - therefore not very conducive to serve as a hedge against inflation, commodities with low liquidity on the financial markets. The resulting 18 price series are described in the table below, and include 9 metals (aluminium, copper, lead, tin, nickel, zinc; and 3 precious metals, gold, silver, platinum), 6 agricultural products (wheat, soybean, corn, coffee, sugar and cotton) and 3 energy products (oil, coal and gas).

\begin{tabular}{|c|c|}
\hline Series & Description \\
\hline Aluminum & $\begin{array}{l}\text { Aluminum (LME) London Metal Exchange, unalloyed primary ingots, high } \\
\text { grade, minimum 99.7\% purity, settlement price beginning 2005; } \\
\text { previously cash price }\end{array}$ \\
\hline Coal & $\begin{array}{l}\text { Coal (Australia), from January 2015, port thermal, f.o.b. Newcastle, } 6000 \\
\mathrm{kcal} / \mathrm{kg} \text { spot price. } 2002-2014 \text {, thermal GAR, f.o.b. piers, Newcastle/Port } \\
\text { Kembla, } 6,300 \mathrm{kcal} / \mathrm{kg}(11,340 \mathrm{btu} / \mathrm{lb}), \text { less than } 0.8 \% \text {, sulfur } 13 \% \text { ash; } \\
\text { previously } 6,667 \mathrm{kcal} / \mathrm{kg}(12,000 \mathrm{btu} / \mathrm{lb}), \text { less than } 1.0 \% \text { sulfur, } 14 \% \text { ash }\end{array}$ \\
\hline Coffee & $\begin{array}{l}\text { Coffee (ICO), International Coffee Organization indicator price, other mild } \\
\text { Arabicas, average New York and Bremen/Hamburg markets, ex-dock }\end{array}$ \\
\hline Copper & $\begin{array}{l}\text { Copper (LME), grade A, minimum } 99.9935 \% \text { purity, cathodes and wire } \\
\text { bar shapes, settlement price }\end{array}$ \\
\hline Corn & Maize (US), no. 2, yellow, f.o.b. US Gulf ports \\
\hline Cotton & $\begin{array}{l}\text { Cotton (Cotton Outlook "CotlookA index"), middling 1-3/32 inch, traded in } \\
\text { Far East, C/F beginning 2006; previously Northern Europe, c.i.f. }\end{array}$ \\
\hline Cruc & $\begin{array}{l}\text { Crude oil, Dubai Fateh } 32^{\prime} \text { API for years 1985-present; } 1960-84 \text { refer to } \\
\text { Saudi Arabian Light, } 34^{\prime} \text { API. }\end{array}$ \\
\hline
\end{tabular}

${ }^{1}$ http://www.worldbank.org/en/research/commodity-markets 


\begin{tabular}{l|l} 
Gold & Gold (UK), 99.5\% fine, London afternoon fixing, average of daily rates \\
\hline $\begin{array}{l}\text { Lead } \\
\text { Natural } \\
\text { gas }\end{array}$ & Lead (LME), refined, 99.97\% purity, settlement price \\
\hline Nickel & $\begin{array}{l}\text { Nickel (LME), cathodes, minimum 99.8\% purity, settlement price } \\
\text { beginning 2005; previously cash price }\end{array}$ \\
\hline Platinum & Platinum (UK), 99.9\% refined, London afternoon fixing \\
\hline Soybeans & $\begin{array}{l}\text { Soybeans, US No. 2 yellow meal, CIF Rotterdam beginning December } \\
\text { 2007; previously US origin, nearest forward. }\end{array}$ \\
\hline Sugar & $\begin{array}{l}\text { Sugar (world), International Sugar Agreement (ISA) daily price, raw, f.o.b. } \\
\text { and stowed at greater Caribbean ports }\end{array}$ \\
\hline Tin & $\begin{array}{l}\text { Tin (LME), refined, 99.85\% purity, settlement price } \\
\text { Wheat }\end{array}$ \\
$\begin{array}{l}\text { Wheat (US), no. 1, hard red winter, ordinary protein, export price } \\
\text { delivered at the US Gulf port for prompt or 30 days shipment }\end{array}$ \\
\hline $\begin{array}{l}\text { Zinc (LME), high grade, minimum 99.95\% purity, settlement price } \\
\text { beginning April 1990; previously special high grade, minimum } 99.995 \%, \\
\text { cash prices }\end{array}$
\end{tabular}

\section{Table 1: Description of commodity price series}

As we aim to measure the ability of gold to hedge against inflation, we need to measure inflation. We follow the literature and take the seasonally adjusted monthly US CPI available on the FRED data server of the Federal Reserve of St. Louis. ${ }^{2}$

\subsection{Inflation Hedging}

According to Bodie (1976) and Arnold and Auer (2015), there are three definitions of inflation hedging. In the first one, an asset is an inflation hedge if it reduces the possibility that its real return falls below zero or any other prespecified value. In this view, an asset with a rising real price (and low variance) would be an inflation hedge. The second definition measures the inflation hedging power by the reduction of the variance of the real return of a portfolio combining the asset and a risk-free bond. Finally, the third definition considers an asset to be an (perfect) inflation hedge if its nominal return is (perfectly) positively correlated with inflation. We use this last definition, one of its key advantages being its least dependence to the time window, another one being its wide use in the empirical literature on inflation hedging, and therefore its comparability potential.

Our assessment of the inflation hedging power is based on testing the (non-) stationarity of the real commodity prices. A commodity whose nominal return is perfectly correlated with inflation will have a constant real price. If the correlation only operates in the long run, the real price will revert to its mean, that is, it will be stationary. If the correlation does not operate in the short nor in the long run, then the real price will not revert to a mean and will be found as non-stationary.

We operate our analysis by comparing gold with the other commodities. As discussed in Arnold and Auer (2015), general commodities are potential inflation hedges. Gold is the most investigated one but not the only commodity to be considered for inflation

\footnotetext{
${ }^{2}$ https://fred.stlouisfed.org/series/CPIAUCSL/
} 
hedging. Bodie (1983), Gorton and Rouwenhorst (2006), Kat and Oomen (2007), Spierdijk and Umar (2014), among others, analyzed commodities through global indices, commodity groups and granularly. Gorton and Rouwenhorst (2006) found that commodities, contrary to common stocks or bonds, are positively correlated with inflation on most time windows. Spierdijk and Umar (2014) assessed the hedging properties of commodity futures over 1970-2011 for the S\&P GSCl and separately for 5 five sub-groups. They concluded that energy, industrial metals and live cattle have better hedging properties than precious metals or agricultural goods. Kat and Oomen (2007) showed that commodity futures returns were positively correlated with unexpected inflation (i.e. $25 \%$ on average with CPI inflation as opposed to $-30 \%$ for equities and $-50 \%$ for bonds) and found significant differences between the various commodities, with energy, metals, cattle, and sugar offering the best hedging potential.

\subsection{Non-stationarity tests}

The golden constant theory predicts that the real price of gold is constant over the long term, in other words that the real price of gold oscillates around this constant, only deviating from it temporarily. We test this hypothesis of stationary real price for gold and our alternative commodities via a set of three unit-root tests. We expect from a commodity with constant purchasing power to have a stationary real price, that is, to reject the null of non-stationary for our first two unit-root tests, or to non-reject the null of stationarity for our third unit root test.

The standard test is the Dickey-Fuller one (Dickey and Fuller, 1979). If the null hypothesis is rejected, the series is stationary, in the sense that it oscillates around a constant. We will submit each of the commodities to this test, so that we can classify the series according to the force with which the null hypothesis is rejected, that is, the force with which the real prices are recalled towards their constant. The test is based on the augmented Dickey-Fuller model, reproduced below

$$
\Delta y_{t}=\alpha+\gamma y_{t-1}+\sum_{j=1}^{p} \delta_{j} \Delta y_{t-j}+\varepsilon_{t}
$$

Where $y_{t}$ is the (real) price of the commodity, where $\alpha$ is a constant, where $\gamma$ is the coefficient on which the null hypothesis of non-stationarity relates, $H_{0}: \gamma=0$ vs $H_{a}: \gamma<$ 0 , where the $p$ lagged dependent variables $\Delta y_{t-j}$ behind the summation symbol aim to capture the residual dynamics, and where $\varepsilon_{t}$ is a white noise. The comparison of the commodities is based on the t-statistics of $\gamma$. The most negative the value of the tstatistics, the stronger the rejection of the null of non-stationarity, the stronger the support to the constant purchasing power of the commodity.

The Dickey-Fuller test is known to lack power, that is, it tends not to reject the null hypothesis enough, even when the alternative hypothesis is true. In other words, this test tends to conclude too frequently the non-rejection of the non-stationarity. We will therefore use three complementary tests to verify the robustness of our results.

Firstly, we perform the test of Zivot and Andrews (1992), which incorporates the possibility of a structural change (a change in the level of the constant). Knowing that the Dickey-Fuller test can confuse a structural change with an absence of unconditional return to the mean, the Zivot-Andrews test makes it possible to test the sensitivity of the conclusions of the first test. The variant of the Zivot-Andrews test that we are testing is similar to the Dickey-Fuller model, with the exception that an indicator 
variable $D_{t}$ is added, which takes the value 1 for observations on, or consecutive to, the arbitrary date BT (Break Time), and 0 for earlier dates. The test parameter remains $\gamma$, but it is no longer unique since the estimate is repeated for each possible value of BT. The conclusion of the test is taken on the basis of the minimum value of the test statistic of $\gamma$. As for the precedent unit-root test, the comparison of the commodities is based on the t-statistics of $\gamma$. By comparison with the Dickey-Fuller test, this methodology favors the rejection of the null hypothesis.

$$
\begin{gathered}
\Delta y_{t}=\alpha+\gamma y_{t-1}+\theta D_{t}+\sum_{j=1}^{p} \delta_{j} \Delta y_{t-j}+\varepsilon_{t} \\
D_{t}= \begin{cases}0, & t<B T \\
1, & t \geq B T\end{cases}
\end{gathered}
$$

One limit of the Zivot-Andrews test is the assumption of the absence of structural break under the unit-root null hypothesis. Therefore, the rejection of the null does not necessarily mean a rejection of the null hypothesis of a unit root but might as well be induced by the presence of a break (Carpantier, 2020). We therefore rely on an alternative unit root test proposed by Lee and Strazicich (2003), which allows for two structural breaks under the null hypothesis, and thus does not suffer from the size distorsion of the Zivot-Andrews test.

Finally, we rely the 4th unit-root test, known as the KPSS test (Kwiatkowski et al., 1992), which differs from the previous ones in that it no longer takes nonstationarity of real commodity prices as the null hypothesis but as the alternative hypothesis. By reversing the null hypothesis, this test makes it possible to detect inconsistencies due to the lack of power of the Dickey-Fuller, Zivot-Andrews and LeeStrazicich tests.

\subsection{Half-life adjustments}

The previous section made it possible to establish whether real prices oscillate around a constant or not. We focus here on the half-life adjustments, that is, the average time that a series takes to cover half the distance which separates it from its constant, that is, from its unconditional average (half-life deviation). The quicker a real price series regain its average, the more the idea of a constant is reinforced, the more effective the protection against from the point of view of the investor.

To assess the speed of adjustment, we subject our series to three statistical measures of the speed of convergence (half-life). Given that the stationarity hypotheses of the series determine the choice of statistical models, and that the unitroot tests carried out do not allow a firm ruling on the nature of the real prices of commodities (not surprisingly, since other studies, notably Chevallier and lelpo (2013) arrive at the same observation), we follow an agnostic approach by presenting the results as a whole, according to 3 methods designed for stationary, quasi-stationary and cointegrated non-stationary series. This will allow the reader to have a comprehensive and critical view on the results and conclusions. The halflife deviation, $h$, is first estimated using the following formula

$$
h=\frac{\ln (0.5)}{\ln \left(\sum_{j=1}^{p} \hat{\beta}_{j}\right)}
$$


where the denominator, $\ln \left(\sum_{j=1}^{p} \hat{\beta}_{j}\right)$, is obtained via the estimation of an autoregressive model of order $p$ by the ordinary least squares (OLS) method such as that reproduced below

$$
y_{t}=\alpha+\sum_{j=1}^{p} \beta_{j} y_{t-j}+\varepsilon_{t}
$$

As detailed in the article of Dias and Marques (2010) dedicated to persistence measures, this formula provides a first approximation of the half-life of stationary series.

As the OLS estimator suffers from downward bias in small samples, and inconsistency when the estimated series is close to non-stationarity, we recalculate the half-life by replacing the OLS estimator of $\beta_{j}$ by the unbiased median estimator of Roy and Fuller (2001). This estimator is designed to correct the bias resulting from the estimation of variables close to non-stationarity.

Our third half-life statistic is based on tools developed for cointegrated non-stationary series. As the hypothesis of non-stationarity is not rejected for a good number of real commodity prices (in our study, but also in the literature), and as the hypothesis of a long-term relationship (the so-called cointegration relationship) between the price of gold and the $\mathrm{CPI}$ is the heart of the golden constant, we now consider the "error correction model" (ECM).

The error correction model is a dynamic model of the dollar price of the commodity that distinguishes short-term influences from long-term influences. The short term is captured by an autoregressive model of order $p$, while the long term is captured by an "error" (hence the name of the error correction model) calculated as the deviation from the long-term equilibrium between the dollar price of the commodity and the CPI. This model is formulated as follows

$$
\Delta y_{t}=\alpha+\beta \Delta x_{t}+\gamma\left(y_{t-1}-\varphi x_{t-1}\right)+\varepsilon_{t}
$$

Where $y_{t}$ is the dollar price of the commodity, where $\alpha$ is a constant, where $x_{t}$ is the $\mathrm{CPI}$, where the term in parenthesis is the long-term imbalance between the price of the commodity and the CPI measured in $t-1$, what is called " error ", and where $\gamma$ measures the impact of this long-term imbalance on the price dynamics of the commodity. The parameter $\gamma$ is in principle negative (otherwise the differences between series would tend to increase). The larger the absolute value of $\gamma$, the faster the deviation from equilibrium is absorbed, the greater the speed of a return to equilibrium. The half-life is calculated in this context as

$$
h=\frac{\ln (0.5)}{\ln (1+\gamma)}
$$

We classify and compare the commodities according to these 3 half-life statistics. Commodities with small half-lives are those offering the most stable purchasing power and the best safeguard against inflation. 


\section{Results and Discussions}

\subsection{Results}

The first of our 3 empirical steps (graphical comparisons, non-stationarity tests, convergence speed measurements), is based on the comparative visualization of the golden constant of Erb and Harvey $(2013,2017)$. For this purpose, we compare in a set of time series plots the monthly evolution of the real commodity prices for energy, precious metals, industrial metals and agriculturals (Figure 2) over the period 19752019. We can see that the real price, that is, the commodity purchasing power, is not a constant for any commodity, but on the contrary follows large oscillations far from the expected pattern of a horizontal straight alignment.

The second take-away is that gold does not look a priori different from the other commodities. It deviates largely from its constant, as most other commodities. The statistics and tests that we produce in a second step will make it possible to formally quantify, and compare, the stability of the real commodity prices.

More incidentally, it finally appears that the real price of some commodities substantially declines over the 1975-2019 window, especially for the 6 agricultural materials. This can be related to the Prebisch-Singer Hypothesis, which states that the relative price of commodities declines over the long run (Harvey et al., 2010). 
Energy

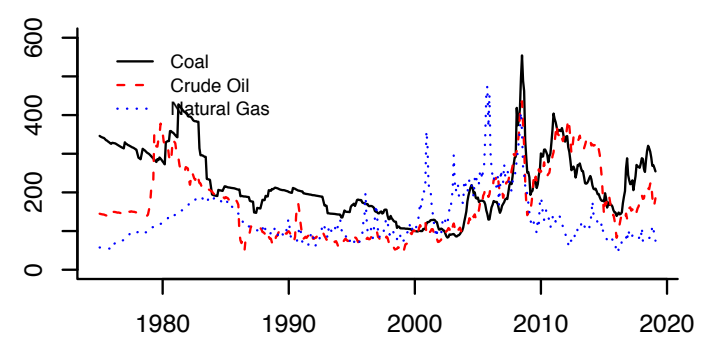

Industrial metals 1

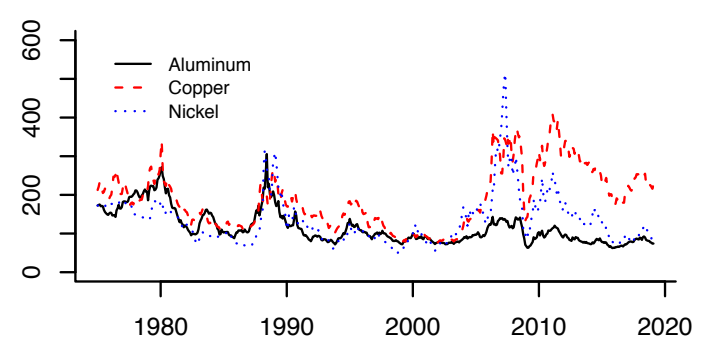

Agriculturals 1

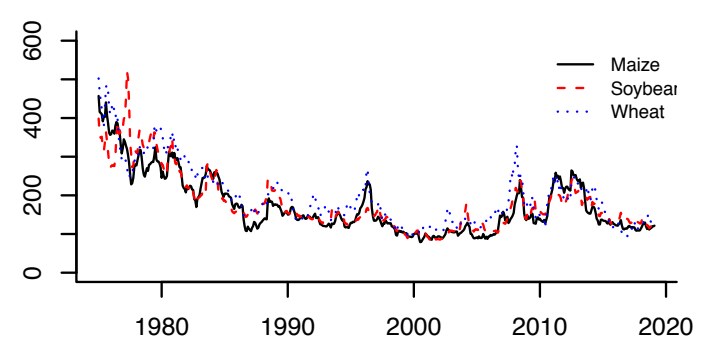

Precious metals

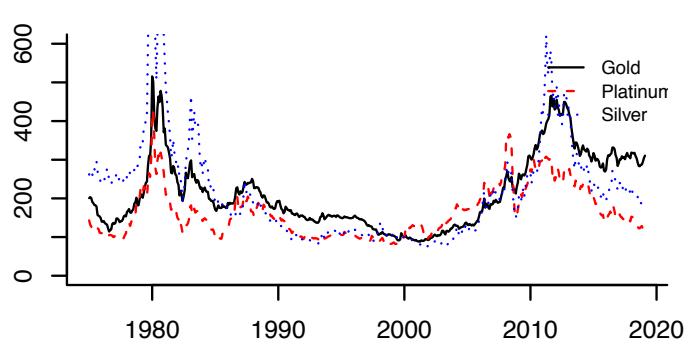

Industrial metals 2

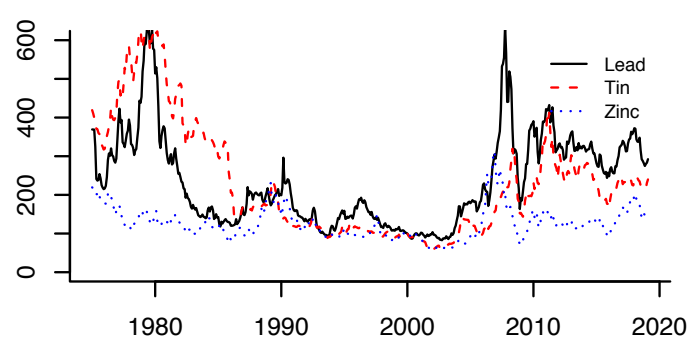

Agriculturals 2

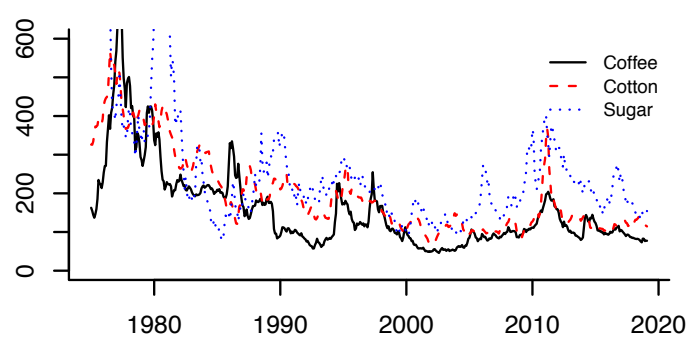

Figure 2: Commodity real prices

The real price is the nominal U.S. dollar price of the commodity "X" divided by the U.S. Consumer Price Index (monthly observations, $2000=100$ ). 
The results of the (non-)stationarity tests of Dickey-Fuller, Zivot-Andrews, LeeStrazicich and KPSS are reported in Table 2. It appears that the real price of gold is the series with the least negative Dickey-Fuller test statistics, that is, the one where stationarity around a constant is the least probable. We reject the null hypothesis in favor of stationarity only for 4 series (sugar, silver, corn, wheat), but it remains that, compared to other series, the real price of gold is the least stationary. ${ }^{3}$ This result might result from the existence of a structural change over the period 1975-2019. This is why we also present the results of the Zivot-Andrews test. Based on it, 10 series of real prices are stationary, which is still not the case for gold. Gold is here again the real price series with the least negative Zivot-Andrews statistics. The Zivot-Andrews tests may suffer from size distortion, as rejection of the null is not necessarily due to stationarity of the series, but might well be due to the existence of a break in the series. We therefore rely on a third stationary test, the Lee-Strazicich test (which allows two breaks under the null hypothesis). We find that non-stationarity is not rejected for any series, and that the real price of gold is still among the 5 least stationary ones. Finally, these three tests may lack power. We thus present the statistics for the KPSS test, which takes the stationarity of the real price series under the null hypothesis (contrary to the previous ones which take stationarity under the alternative hypothesis). The results, reported in the column KPSS show that most of the series are non-stationary, including gold. The conclusion of this analysis is that the real price of gold is among the most non-stationary series, as shown with the 4 tests. Gold does not fluctuate around a constant, unlike some other commodities of the sample.

\begin{tabular}{|c|c|c|c|c|}
\hline & Dickey-Fuller & Zivot-Andrews & Lee-Strazicich & KPSS \\
\hline Aluminum & -1.30 & -4.23 & $-4,394$ & $3.76^{* *}$ \\
\hline Coal & -1.17 & -4.32 & $-4,222$ & $1.45 * *$ \\
\hline Coffee & -1.63 & $-5.64 * *$ & $-3,729$ & 3.69 ** \\
\hline Copper & -1.04 & $-5.42 * *$ & $-3,512$ & 1.69 ** \\
\hline Corn & -2.09 * & -4.51 & $-2,145$ & 3.40 ** \\
\hline Cotton & -1.46 & $-5.66 * *$ & $-3,447$ & 5.11 ** \\
\hline Crude oil & -1.15 & -4.07 & $-3,184$ & 1.32 ** \\
\hline Gold & -0.49 & -3.52 & $-2,630$ & 1.62 ** \\
\hline Lead & -1.34 & -4.48 & $-4,242$ & 1.14 ** \\
\hline Natural gas & -1.61 & $-5.07 *$ & $-3,780$ & 0.71 * \\
\hline Nickel & -1.78 & $-4.81 *$ & $-4,655$ & 0.36 \\
\hline Platinum & -1.15 & -4.29 & $-3,217$ & $1.35 * *$ \\
\hline Silver & $-2.90 * *$ & $-6.44^{* *}$ & $-4,276$ & 1.02 ** \\
\hline Soybeans & -1.67 & $-5.75^{* *}$ & $-2,981$ & 3.72 ** \\
\hline Sugar & $-5.53 * *$ & $-9.96 * *$ & $-1,406$ & 2.20 ** \\
\hline Tin & -1.25 & -3.69 & $-2,002$ & 2.88 ** \\
\hline Wheat & -2.06 * & $-4.84 *$ & $-2,207$ & 3.65 ** \\
\hline Zinc & -1.35 & $-4.83 *$ & $-3,765$ & 0.45 \\
\hline
\end{tabular}

\section{Table 2: (Non-)stationarity tests of real price series}

(2a) The greater the absolute value of the Dickey-Fuller test statistics, the stronger the rejection of the null of non-stationarity of real prices, the stronger the support of the constant purchasing power value. See Equation (1); Optimal lag based on BIC. (2b) The greater the absolute value of the Zivot-Andrews test statistics, the stronger the rejection of the null of non-stationarity of real prices, the stronger the support of the constant purchasing power value. See Equation (2); 1 break. (2c) The greater the

\footnotetext{
${ }^{3}$ Results robust to the inclusion of drift and deterministic trend.
} 
absolute value of the Lee-Strazicich test statistics, the stronger the support of the constant purchasing power value. Optimal lag bfased on BIC. 2 breaks. (2d) The greater the value of the KPSS test statistics, the stronger the rejection of the null of stationarity of real prices, the weaker the support to the constant purchasing power value. Based on monthly observations over the sample 1975/1-2019/2. Tests described in sub-section 2.2 .

The third statistical piece of this analysis is based on the speed of convergence, measured here by the half-lives, or the time that the series takes to fill half the distance which separates it from its unconditional average. We saw in the previous section that the stationary nature of the real commodity price series was not well established, some series being stationary, others close to non-stationarity, others finally nonstationary. The 3 columns of Table 3 are designed respectively for these 3 specific cases. According to the stationarity case (column AR3), the real price of gold reverts only slowly to its mean as it takes 77 months to cover half the distance to its unconditional average, only cotton and tin being slower with 85.7 and 94 months, respectively. According to the Roy-Fuller estimator designed for quasi-stationary series (column RF), gold is even the slowest, as our econometric software approximates its half-life by infinity. The half-lives of all other commodities are inferior/finite. Finally, we consider the non-stationarity case where commodity prices and consumer price levels are cointegrated and report the half-life adjustment of the error correction term (column ECM). It turns out that the error correction mechanism of gold operates more slowly than for any other commodity, as it takes 104 months to correct half the distance from equilibrium. The half-life value of tin, the second slowest commodity, is equal to 57 months. To summarize, all measures consistently confirm that the ability of gold to keep a constant purchasing power and isolate from the risk of inflation is relatively poor. When it comes to isolating from the risk of inflation, we find that gold is dominated by nearly all the commodities of our sample.

\begin{tabular}{lrrr} 
& AR3 & RF & ECM \\
\hline Aluminum & 34.5 & 58.3 & 14.1 \\
Coal & 31.3 & 42.7 & 25.3 \\
Coffee & 37.3 & 52.5 & 23.3 \\
Copper & 35.5 & 54.8 & 29.1 \\
Corn & 34.5 & 43.1 & 29.1 \\
Cotton & 85.7 & 282.9 & 19.6 \\
Crude oil & 38.2 & 56.6 & 28.5 \\
Gold & 77.2 & Inf & 104.0 \\
Nickel & 22.0 & 26.6 & 24.3 \\
Lead & 34.9 & 54.5 & 29.4 \\
Natural gas & 13.3 & 15.8 & 11.8 \\
Platinum & 33.8 & 52.5 & 32.6 \\
Silver & 16.7 & 20.4 & 24.3 \\
Soybeans & 33.4 & 44.9 & 22.5 \\
Sugar & 13.0 & 14.0 & 12.1 \\
Tin & 94.0 & 4838.2 & 57.7 \\
Wheat & 33.8 & 42.8 & 21.4 \\
Zinc & 20.8 & 25.0 & 26.0
\end{tabular}

Table 3: Half-life adjustments

The table reports the half-life, that is, the average time, expressed in months, required for real commodity prices to cover half the distance to their unconditional mean (columns 2 and 3 ) or required for nominal commodity prices and U.S. CPI to get back to their equilibrium relationship (column 4). The smaller the values, the faster the adjustment, the more stable the purchasing power constant. This time is equal to $\ln (1 / 2) / \ln (\varphi)$, where $\varphi$ is the cumulative value 
of the 3 coefficients of an AR (3) model estimated by OLS (column AR3), by the non-biased median estimator of Roy-Fuller (column RF) and is equal to $\ln (1 / 2) / \ln (1+\gamma)$, where $\gamma$ is the coefficient of the error term of the ECM model (column ECM). Based on monthly observations over the sample 1975/1-2019/2.

\subsection{Discussion}

Our results are in line with those of Kat and Oomen (2006) and Spierdijk and Umar (2014), as both found that energy, industrial metals, live cattle had better hedging properties than precious metals. We have no conclusive view on the mechanisms explaining the hedging behavior of these different commodity groups, but we note that three potential complementary explanations might play a role.

First, Erb and Harvey (2006) studied whether commodity futures are good hedges against unexpected inflation, by regressing the commodity futures returns on unexpected inflation. They noted that the average roll returns (return generated by selling the expiring futures contract and buying the next to expire futures contract) explained 67 percent of the cross-sectional variation of commodity futures unexpected inflation betas. Some commodities (e.g., copper, heating oil, and live cattle) had positive roll returns for the period and high unexpected inflation betas. Other commodities (e.g., wheat) had negative roll returns and negative unexpected inflation betas. They concluded that the commodities known to be difficult to store (heating oil, copper, live cattle, live hogs) "had both high roll returns and positive unexpected inflation betas." It could thus explain why some difficult-to-store commodities, such as natural gas, are better hedges than easy-to-store ones, such as gold.

Second, CPI and commodity price series are related by construction, as commodity prices account for about $40 \%$ of the CPI basket, energy commodities making up "only about 4 percent of the CPI, food commodities constitute about 14\%" (Erb and Harvey (2006)). This would partially explain the good hedging performance of food commodities (sugar, wheat).

Finally, the short-run volatility of the commodities differs (and the way fundamentals affect this volatility also differs) from one commodity to the other. The theoretical model of Ghosh et alii (2004) demonstrated the conditions under which gold can be an effective hedge against inflation. Their model incorporated as source of short-run volatility the convenience yield, the supply (in)elasticity, the covariance of gold returns with other assets. The non-uniform exposure of commodities to these fundamentals provides the third potential explanation of commodity heterogeneity in inflation hedging power.

Independently from the mechanisms explaining the inflation hedging properties of these different commodity groups, we complement our analysis by investigating whether the non-stationarity of the real prices is associated to the existence of breaks, that is, from sudden shifts in the constant. We therefore identify break dates for each real price series by relying on the algorithm described in Bai and Perron (2003) for simultaneous estimation of multiple breakpoints and whose implementation is described in Zeileis et al. (2003). We report the break dates in Table 4. We first find that the non-stationarity of commodity real prices and the multiplicity of regimes with different "constants" are two faces of the same coin, as most real price series have from 3 to 5 breaks (4 to 6 regimes). This result documents the weak power of all commodities, including gold, to keep an unconditionally constant purchasing power. 
We finally note that some breaks are clustered around 1981 (US recession), 1990 (US recession), 1998 (South-East Asian crisis) and 2007 (Great recession), which confirms the partial commonality of real commodity prices, driven by common factors such as global business cycle and global monetary conditions.

\begin{tabular}{ll}
\hline Aluminum & $1981(7) ; 1990(11) ; 1998(2) ; 2005(8) ; 2012(3)$ \\
Coal & $1983(6) ; 1992(10) ; 2007(6)$ \\
Coffee & $1981(7) ; 1989(5) ; 1999(6) ; 2007(8)$ \\
Copper & $1981(7) ; 1988(2) ; 1996(5) ; 2005(11) ; 2012(7)$ \\
Corn & $1981(7) ; 1989(5) ; 1998(3) ; 2006(10)$ \\
Cotton & $1981(7) ; 1991(6) ; 1998(9) ; 2009(12)$ \\
Crude oil & $1986(1) ; 2005(5) ; 2012(7)$ \\
Gold & $1989(1) ; 1996(6) ; 2003(1) ; 2009(8)$ \\
Nickel & $1981(7) ; 1988(2) ; 1994(9) ; 2005(1) ; 2012(3)$ \\
Lead & $1981(10) ; 1991(4) ; 2006(8)$ \\
Natural gas & $1981(7) ; 1988(2) ; 1995(11) ; 2002(8) ; 2009(3)$ \\
Platinum & $1981(10) ; 1990(9) ; 1999(5) ; 2005(12) ; 2012(7)$ \\
Silver & $1984(4) ; 1990(11) ; 2006(3)$ \\
Soybeans & $1981(7) ; 1989(7) ; 1998(4) ; 2007(5)$ \\
Sugar & $1981(8) ; 1998(2) ; 2009(3)$ \\
Tin & $1983(11) ; 1990(6) ; 2007(1)$ \\
Wheat & $1982(5) ; 1990(4) ; 1997(11) ; 2005(12) ; 2012(7)$ \\
Zinc & $1981(9) ; 1992(10) ; 2005(10) ; 2012(5)$ \\
& \\
& Table 4: Break Dates \\
The table reports the break dates of the real commodity price series, based on the algorithm described in Bai \\
and Perron (2003) for simultaneous estimation of multiple breakpoints and whose implementation is described \\
in Zeileis et al. (2003). Minimal segment size 0.15. Based on monthly observations over the sample 1975/1- \\
2019/2.
\end{tabular}

\section{4. $\underline{\text { Conclusions }}$}

The golden constant is a concept not well supported by the data. Our analysis suggests that it would be less inconsistent to speak of a nickel constant or a zinc constant, than of a golden constant.

We first illustrated, graphically, the wide fluctuations of the real price of gold, and showed that they were in line with the ones of the 17 commodities of our control sample (energy, metals, agriculturals). We then investigated and compared the constant purchasing power property of these commodities through a battery of convergence speed measures and of (non)stationarity tests. We find that the real price of gold is not statistically characterized by stationarity around a constant. Our results all suggest that the real price of gold is wandering without return towards any constant purchasing power. Further, we find that the nonstationarity of the real price series is statistically stronger for gold than for the other commodities.

Does it mean that gold is a poor hedge against inflation - poorer than industrial metals or energy? No; other dimensions must be considered, such as the evolution of gold 
price relative to inflation. Still, in a period of high gold market price, it is useful not to forget that other commodities prove at least as efficient vehicles as, or better than, gold for keeping a constant purchasing power.

In a recent study on the safe haven property of gold, Baur and McDermott (2016) showed that behavioural biases help to explain the perception of gold as a safe haven, while the safe-have effect disappears relatively quickly for gold, and that the asset is more volatile and risky than alternative ones such as US Treasury bonds. Whether similar behavioural biases are behind this view that gold is the panacea against inflation would not come as a surprise.

\section{$\underline{\text { References }}$}

Arnold, Stephan, and Benjamin R. Auer. 2015. "What do scientists know about inflation hedging?", North American Journal of Economics and Finance, 34: 187-214.

Bai, Jushan, and Pierre Perron. 2003. "Computation and Analysis of Multiple Structural Change Models", Journal of Applied Econometrics, 18: 1-22.

Batten, Jonathan A., Cetin Ciner, and Brian M. Lucey. 2014. "On the economic determinants of the gold inflation relation", Resources Policy, 41 (C): 101-108.

Baur, Dirk G., and Thomas K. McDermott. 2010. "Is gold a safe haven? International evidence", Journal of Banking \& Finance, 34 (8): 1886-1898.

Baur, Dirk G., and Thomas K. McDermott. 2016. "Why is gold a safe haven?", Journal of Behavioral and Experimental Finance, 10: 63-71.

Baur, Dirk G., and Brian M. Lucey. 2010. "Is Gold a Hedge or a Safe Haven? An Analysis of Stocks, Bonds and Gold", The Financial Review, 45 (2): 217-229.

Bodie, Zvi. 1976. "Common Stocks as a Hedge against Inflation", Journal of Finance, 31(2): 459-470.

Bodie, Zvi. 1983. "Commodity Futures as a Hedge against Inflation", Journal of Portfolio Management, 9(3): 12-17.

Capie, Forrest, Terence C. Mills, and Geoffrey Wood. 2005. "Gold as a hedge against the dollar", Journal of International Financial Markets, Institutions and Money, 15 (4): 343-352.

Carpantier, Jean-François. 2020. "Commodity Prices in Empirical Research", forthcoming in Recent Econometric Techniques for Macroeconomics and Finance, Ed. G. Dufrénot and T. Matsuki, Springer.

Chevallier, Julien, and Florian lelpo. 2013. "The Economics of Commodity Markets", Wiley Finance.

Coudert, Virginie, and Hélène Raymond-Feingold. 2011. "Gold and financial assets: Are there any safe havens in bear markets?" Economics Bulletin, 31 (2): 1613-1622. 
Dias, Daniel, and Carlos R. Marques. 2010. "Using mean reversion as a measure of persistence", Economic Modelling, 27 (1): 262-273.

Dickey, David A., and Wayne A. Fuller. 1979. "Distribution of the Estimators for Autoregressive Time Series with a Unit Root", Journal of the American Statistical Association, 74 (366): 427-431.

Erb, Claude B., and Campbell R. Harvey. 2006. "The Strategic and Tactical Value of Commodity Futures", Financial Analysts Journal, 62: 69-97.

Erb, Claude B., and Campbell R. Harvey. 2013. "The Golden Dilemma”, Financial Analysts Journal, 69 (4): 10-42.

Erb, Claude B., and Campbell R. Harvey. 2017. "The Golden Constant", The Journal of Investing, 26 (1): 94-100.

Ghosh, Dipak, Eric J. Levin, Peter MacMillan, and Robert E. Wright. 2004. "Gold as an Inflation Hedge", Studies in Economics and Finance, 22(1): 1-25.

Gorton, Gary and K. Geert Rouwenhorst. 2006. "Facts and Fantasies about Commodity Futures", Financial Analysts Journal, 62(2): 47-68.

Harvey, David I., Neil M. Kellard, Jakob M. Madsen, and Mark E. Wohar. 2010. "The Prebisch-Singer hypothesis: four centuries of evidence", Review of Economics and Statistics, 92: 367-377.

Kat, Harry M., and Roel C. Oomen. 2006. "What Every Investor Needs to Know About Commodities: Multivariate Return analysis", Journal of Investment Management, 5(3).

Kwiatkowski, Denis, Peter C. B. Phillips, Peter Schmidt, and Yongcheol Shin. 1992. "Testing the null hypothesis of stationarity against the alternative of a unit root", Journal of Econometrics. 54 (1-3): 159-178.

Lee, Junsoo, and Mark C. Strazicich. 2003. "Minimum Lagrange Multiplier Unit Root Test with Two Structural Breaks", The Review of Economics and Statistics, 85(4): 1082-1089.

Piffer, Michele, and Maximilian Podstakski. 2018. "Identifying Uncertainty Shocks Using the Price of Gold”, Economic Journal, 128 (616): 3266-3284.

Pukthuanthong, Kuntara, and Richard Roll. 2011. "Gold and the Dollar (and the Euro, Pound, and Yen)", Journal of Banking \& Finance, 35 (8): 2070-2083.

Roy, Anindya, and Wayne A. Fuller. 2001. "Estimation for autoregressive time series with a root near one", Journal of Business \& Economic Statistics, 19 (4): 482-493.

Spierdijk, Laura, and Zaghum Umar. 2014 "Are commodity futures a good hedge against inflation?", Journal of Investment Strategies, 3(2): 35:57.

Zeileis, Achim, Christian Kleiber, Walter Krämer, and Kurt Hornik. 2003. "Testing and Dating of Structural Changes in Practice", Computational Statistics and Data Analysis, 44: 109-123. 
Zivot, Eric, and Donald W. K. Andrews. 1992. "Further evidence on the great crash, the oil-price shock, and the unit-root hypothesis", Journal of Business and Economic Statistics, 10: 251-270. 


\section{INSTITUT DE RECHERCHE ÉCONOMIQUES ET SOCIALES}

Place Montesquieu 3

1348 Louvain-la-Neuve

ISSN 1379-244X D/2020/3082/36 